\title{
Sobre letras e cinema: entrevista com Randal Johnson
}

Antonio Dimas 
Randal Johnson vem construindo sua carreira acadêmica sob a marca da exemplaridade, dividindo-a, de forma equilibrada, entre docência, pesquisa e envolvimento institucional. Neste item, além da chefia dos Departamentos das universidades em que atuou e atua, esteve à frente, também, do Latin American Institute e do setor de Relações Internacionais da University of California, em Los Angeles, onde ingressou, como professor de Literatura Brasileira, em 1994.

Depois de alcançar seu doutoramento pela University of Texas, em Austin, em 1977, Randal Johnson lecionou na Rutgers University (1977-83) e na University of Florida (1983-94).

Seu primeiro livro em português - Literatura e cinema: Macunaíma: do modernismo na literatura ao cinema novo (1982) - espelha com clareza sua inclinação comparatista e sua dedicação a dois campos expressivos de nossa cultura: a literatura e o cinema. Ao longo dos anos, seus cursos de pós-graduação, suas participações em congressos, simpósios e festivais e sua bibliografia atestam seu envolvimento com nossa contemporaneidade. Sobre seus projetos em andamento - expansão, aprofundamento e contextualização mais ampla de suas pesquisas anteriores, o que é evidência de continuidade macia e sem trancos oportunistas - , ouçamos seu depoimento.

\section{Como teve início seu interesse intelectual pelo Brasil? Onde estão essas raízes? Quais os especialistas nessa área que o ajudaram, de forma direta ou indireta? Qual a relevância da contribuição desses antecessores?}

Meu interesse intelectual pelo Brasil surgiu através de um interesse pessoal, e dentro de circunstâncias bastante precisas. Quando ingressei na faculdade como aluno de graduação, eu não tinha uma noção específica do que queria estudar. Estava interessado na América Latina por causa de duas viagens que havia feito ao México e estava pensando em estudar relações internacionais. Já falava espanhol. Aí, depois do primeiro ano de faculdade, sabendo que a universidade ia começar a oferecer matérias de português, comprei um LP de João Gilberto cantando músicas de Tom Jobim. Foi com esse LP que descobri o Brasil. A partir daí foi uma bola de neve. Com certeza, minha imagem do país era extremamente idealizada e romântica, naquele momento. Uma imagem reforçada pelo filme Orfeu Negro [1959, de Marcel Camus], que circulava muito nas universidades. Isto era a época da guerra do Vietnã, da Guerra Fria, do movimento pelos direitos civis e assim por diante, e a sombra da convocação militar pairava sobre minha cabeça. Como disse em outras ocasiões, entre a guerra e um Rio de Janeiro idealizado, 
a opção era fácil. Acabei não sendo convocado e em 1970 entrei na pós-graduação da Universidade do Texas, em Austin, para estudar literatura luso-brasileira.

\section{Quem o orientou nas escolhas acadêmicas específicas?}

A grande figura no estudo de literatura brasileira na Universidade do Texas, naquela época, era Fred P. Ellison, que faleceu o ano passado. Entre muitas outras coisas, o professor Ellison era o autor do livro Brazil's New Novel: Four Northeastern Masters. Era um homem extremamente generoso e meu mentor. Também tive a oportunidade de estudar com Norman Potter, um intelectual impressionante, e vários professores de literatura hispano-americana. Mas no primeiro ano de pós, tive a oportunidade de fazer seminários com Massaud Moisés e Haroldo de Campos, que eram professores visitantes no departamento. Minha formação teórica e metodológica era muito fraca então, e a disciplina do Massaud me foi muito importante pelo que ele ensinou sobre a análise meticulosa de textos literários. A disciplina do Haroldo era mais teórica. Em seu seminário sobre prosa de vanguarda, ele delineou a análise de Macunaíma que seria publicada dois anos depois, em 1973, com o título Morfologia do Macunaíma. O seminário passou um pouco por cima da minha cabeça, mas plantou uma semente que daria frutos mais tarde com minha tese de doutorado sobre Macunaíma: Literatura e cinema. Nela utilizo a metodologia de Haroldo (e de Vladimir Propp), numa análise comparada da estrutura narrativa do romance de Mário de Andrade e do filme de Joaquim Pedro de Andrade. A tese foi publicada em São Paulo em 1982 pela T. A. Queiroz, em tradução de Aparecida de Godoy Johnson.

\section{Quando se deu o início dessa formação e como era, em retrospecto, o panora- ma dos estudos brasileiros nos Estados Unidos desse tempo? Sua universidade de origem ofereceu-lhe condições para essa pesquisa inicial?}

A Universidade do Texas, em Austin, tem - e tinha, quando ingressei na pós - um dos programas mais fortes de estudos brasileiros nos Estados Unidos. Naquela época, havia Richard Graham, no Departamento de História, William Glade em economia, Gerard Béhague em etnomusicologia, Lawrence Graham em ciência política, além de professores visitantes todo ano. Por exemplo, quando estava terminando a tese, fiz um seminário com Affonso Romano de Sant'Anna, que até hoje considero um amigo.

Sempre tive alguma forma de apoio para minha pesquisa, ou através de bolsas ou do que chamamos de "teaching assistantships", em que ensinava português enquanto estudava. Também recebi bolsas externas à universidade: uma da Fulbright para a 
pesquisa de mestrado, que resultou numa dissertação sobre Adonias Filho, e outra da Social Science Research Council e da American Council of Learned Societies para a tese de doutorado. Além disso, a biblioteca da universidade é maravilhosa, uma das melhores dos Estados Unidos na área de estudos latino-americanos.

\section{Como, quando e onde foi seu primeiro contato efetivo com o Brasil? Quem Ihe serviu de ponte, de contato acadêmico, no Brasil?}

Visitei o Brasil brevemente em 1970, num programa de treinamento do Peace Corps (Voluntários da Paz), mas não permaneci no programa, preferindo voltar ao Texas para fazer a pós-graduação. Em 1971, se não me engano, voltei, com o Professor Fred Ellison, para um grande simpósio na USP sobre Estudos Brasileiros. Foi nessa ocasião que conheci pessoas como você e ouvi palestras de figuras brilhantes como Antonio Candido e José Aderaldo Castello, entre várias outras. Com a bolsa da Fulbright, que mencionei acima, passei um ano no Brasil em 1971-72, fazendo pesquisa independente, principalmente na Biblioteca Nacional. Na ocasião, acabei dividindo o ano entre Rio de Janeiro e Salvador. Era muito jovem e tímido e não cheguei a fazer muitos contatos acadêmicos. Através de Fred Ellison, conheci Adonias Filho, no Rio, e encontrei-o de novo - e por puro acaso - em Ilhéus.

\section{Como se deu a pesquisa que o levou ao cotejo entre o livro e o filme Macunaíma? Por que escolheu esse autor? Você tinha um plano teórico prévio ou foram as circunstâncias que ditaram esse rumo?}

De certa maneira abordei este assunto acima. Foi Haroldo de Campos quem me chamou a atenção para o romance de Mário. Ele mencionou o filme, mas não o havia visto quando vim ao Brasil em 1971. Acabei assistindo a ele pela primeira vez numa sala de cinema que existia na Galeria Alaska, em Copacabana, e que hoje é uma igreja evangélica. Se não me falha a memória, lembro-me de ter assistido, mais ou menos na mesma época, a Como era gostoso o meu francês, de Nelson Pereira dos Santos, em outra sala de cinema em Copacabana. Na pós-graduação acabei fazendo algumas disciplinas de cinema, inclusive uma sobre cinema latino-americano com Julianne Burton-Carvajal, uma das maiores especialistas do assunto nos Estados Unidos. Foi com ela que comecei a aprender alguma coisa sobre o Cinema Novo, o novo cinema latino-americano e o cinema brasileiro de modo geral. No entanto, meu contato mais sistemático com o cinema brasileiro veio em 1975-76, quando passei dezoito meses no Brasil fazendo pesquisa para a tese de doutorado. Nesse período assisti a mais de duzentos filmes brasileiros. 
Em suma, a tese de doutorado resultou da conjunção de vários fatores: o seminário de Haroldo, que me ofereceu algumas noções de teoria e um caminho metodológico, pelo menos em termos da análise da narrativa; um interesse maior pelo cinema e um conhecimento maior da linguagem cinematográfica; e o contato com o Cinema Novo e o cinema latino-americano, que ofereceu a contextualização.

Até certo ponto, a minha pesquisa sempre foi circunstancial, baseada num desejo de conhecer melhor algum assunto, e um assunto levava a outro. Escolhi o assunto da tese de doutorado baseado nas circunstâncias que acabei de descrever. Terminado o doutorado, queria organizar um livro de ensaios sobre o cinema brasileiro para publicar nos Estados Unidos. Consegui meu primeiro emprego acadêmico na Rutgers University, no Estado de New Jersey. Ia sempre a Nova York, muitas vezes para ver filmes brasileiros. Numa destas ocasiões, Fabiano Canosa me apresentou a Robert Stam, que tinha terminado seu doutorado em Berkeley e se mudado para Nova York, onde dava (e dá) aula na New York University. O Bob tinha a mesma ideia, e resolvemos trabalhar juntos. O resultado foi o livro Brazilian Cinema, o primeiro livro publicado em inglês sobre o assunto, com colaborações de pessoas como Sérgio Augusto, José Carlos Avellar, JeanClaude Bernardet, Maria Rita Galvão, João Luiz Vieira e Ismail Xavier, entre outros. É um livro com forte inclinação cinemanovista.

No entanto, depois de terminarmos o livro, me parecia que faltava um estudo mais específico sobre os diretores principais do Cinema Novo e comecei a fazer pesquisa com esta finalidade. O resultado foi o livro Cinema Novo x 5: Masters of Contemporary Brazilian Film, que saiu em 1984, com estudos sobre a obra de Joaquim Pedro de Andrade, Cacá Diegues, Ruy Guerra, Glauber Rocha e Nelson Pereira dos Santos. (Deveria ter expandido a seleção para incluir, no mínimo, Leon Hirzman e Paulo César Saraceni.) Foi durante esta pesquisa que percebi, pela primeira vez, a importância das relações entre o cinema brasileiro e o Estado e, após nova pesquisa, publiquei The Film Industry in Brazil: Culture and the State em 1987, disponível em capítulos separados. (em http://digital.library.pitt.edu/cgi-bin/t/text/tex$t$-idx?idno $=31735057894150 ;$ view $=$ toc $; c=$ pittpress $)$.

Desde então, questões relacionadas à indústria e à política cinematográficas têmse constituído em linha central da minha pesquisa.

Quando trabalhava no livro sobre a indústria cinematográfica e o Estado, li Intelectuais e classe dirigente no Brasil, de Sérgio Miceli, publicado em 1979. Havia feito vários seminários de pós sobre diversos aspectos do movimento modernista, mas ninguém tinha falado da relação às vezes problemática entre alguns escritores modernistas 
e o Estado nos anos 30, e isso passou a me interessar. De volta à Flórida - mudei-me de Rutgers para a Universidade da Flórida em 1983 - , participei de um grupo de trabalho sobre cultura e Estado. Um sociólogo chileno, Hernán Vera, sugeriu que começássemos com a leitura do livro A reprodução, de Pierre Bourdieu e Jean-Claude Passeron. Ao mesmo tempo, sugeri que convidássemos Sérgio Miceli como professor visitante, o que efetivamente aconteceu em 1987. Naquele mesmo ano, formulei um projeto de pesquisa sobre o que chamava de as "relações sociais" da literatura brasileira nos anos 30 e passei o ano letivo seguinte no Woodrow Wilson International Center for Scholars, em Washington, iniciando a investigação.

Com o Sérgio tenho uma dívida intelectual enorme. Foi ele que me abriu as portas para que eu passasse um semestre sabático em Paris, frequentando o grupo de Bourdieu no Centre de Sociologie Européenne. Lá tive a oportunidade de me reunir com Bourdieu e sugeri a ele a organização de um livro de seus ensaios sobre literatura e cultura. O resultado foi The Field of Cultural Production: Essays on Art and Literature, que saiu em 1993, para o qual escrevi a introdução e servi como tradutor e editor de tradução. Este livro representou a primeira de várias digressões que atrasaram o projeto sobre os anos 30 .

Em seguida, organizei um livro em homenagem a Fred Ellison, chamado Tropical Paths: Essays on Modern Brazilian Literature, e outro, com Larry Crook, intitulado Black Brazil: Culture, Identity and Social Mobilization, que inclui trabalhos apresentados num simpósio que organizamos na Universidade da Flórida em 1993. Escrevi um livreto sobre O Dragão da Maldade contra o Santo Guerreiro, de Glauber Rocha, para uma pequena editora na Inglaterra, e continuei trabalhando com a obra de Bourdieu, servindo como tradutor ou editor de Practical Reason (Razões práticas, em português) e das intervenções de Bourdieu, no livro Free Exchange, um longo diálogo entre o sociólogo e o artista alemão Hans Haacke.

Mais uma digressão, que mostra de novo o lado às vezes circunstancial da pesquisa: no final dos anos 9o, assisti, num período relativamente curto, a três filmes que se passam em ou por Portugal: Terra estrangeira, de Walter Salles, $O$ céu de Lisboa, de Wim Wenders, e Viagem ao princípio do mundo, de Manoel de Oliveira. Esses filmes me deram vontade de passar um tempo em Portugal, aprender mais sobre o cinema português e escrever um livro sobre o assunto. Durante um semestre em Lisboa, assisti a muitos filmes. Estava pensando em como iria organizá-lo, quando recebi um convite da editora da Universidade de Illinois para escrever um livro apenas sobre Manoel de Oliveira. Aceitei, e o livro saiu em 2007. Ao longo desse período de digressões, nunca 
deixei de escrever ensaios sobre diversos aspectos do cinema brasileiro e outros assuntos e nunca esqueci o projeto sobre as relações sociais da literatura brasileira, embora a possibilidade de terminá-lo às vezes parecesse distante. Além disso, nos últimos dez anos, tenho ocupado cargos administrativos bastante pesados na University of California, em Los Angeles, o que fragmenta o tempo e atrapalha a pesquisa. Enfim, o trabalho intelectual nem sempre segue em linha reta.

\section{Que tipo de material documental você privilegiou em suas pesquisas no Brasil? Quais foram as dificuldades para ter acesso a esse material? Qual era o esta- do de conservação dos acervos em que trabalhou? Quais suas sugestões para melhor conservá-los e fazê-los funcionar de forma efetiva?}

As coisas mudaram muito desde que comecei a fazer pesquisa no Brasil. Em termos de documentação para a tese de doutorado, usei o arquivo de Mário de Andrade no Instituto de Estudos Brasileiros (e Telê Porto Ancona Lopez foi extremamente generosa com o seu tempo e suas sugestões) e outros materiais na Cinemateca Brasileira, na Biblioteca Municipal Mário de Andrade, no Museu Lasar Segall, em São Paulo, e na Biblioteca Nacional e na Cinemateca do MAM, no Rio de Janeiro. Nunca tive dificuldade de acesso, mas também nunca pedi para ver nada que não estivesse disponível a todos os pesquisadores.

A questão do cinema era mais complicada. Não havia filmes em vHs, muito menos DVD. O negócio era acompanhar mostras, lançamentos, retrospectivas. Lembrome de ter assistido a filmes no centro de São Paulo com gatos (e quem sabe que mais?) andando pelo corredor. Ainda por cima, quem estudava cinema tinha que tomar notas no escuro, muitas vezes escrevendo em cima do que havia acabado de escrever. Hoje as coisas são bastante diferentes.

Para fazer a análise do filme Macunaíma, usei uma cópia em $16 \mathrm{~mm}$, que mandei fazer no Líder, no Rio de Janeiro, com a autorização de Joaquim Pedro. Hoje a cópia se encontra no UCLA Film and Television Archive. Fiz uma análise plano por plano do filme numa moviola da ECA, com a ajuda de Jair Leal Piantino.

Os acervos do IEB me pareceram muito bem organizados e fáceis de consultar. Seria ótimo se tudo fosse digitalizado e disponibilizado na internet. Parece que estamos a caminho disso mesmo, como se vê na Biblioteca Brasiliana José e Guita Mindlin, entre muitas outras. Uma coisa que tem sido muito útil é a disponibilidade de teses defendidas na usP e em várias outras universidades brasileiras. Agora, as trocas de informações são de fato globais. 


\section{Quais são seus projetos em andamento?}

Estou retomando o projeto sobre as relações sociais e políticas da literatura brasileira nos anos 30, que se concentra em quatro escritores: Mário de Andrade, Cassiano Ricardo, Octávio de Faria e Graciliano Ramos. Eles representam duas gerações literárias, quatro posições políticas distintas e quatro diferentes modos de inserção no campo. Dois fazem parte do cânone literário; os outros dois nem tanto. Em termos políticos, Cassiano Ricardo e Octávio de Faria ocupam posições de direita. O primeiro era leigo; o segundo, católico, mas os dois eram autoritários. Mário é mais de centro e Graciliano, de esquerda.

Trabalho com um conceito elaborado por Edward Said. Com a ideia de que os textos literários constituem uma rede dinâmica de relações sociais, intimamente vinculadas a relações sutis de autoridade e de poder. Este poder não se refere necessariamente ao poder do Estado; pode se referir ao poder simbólico dentro do campo literário, onde existem hierarquias de vários tipos. Alguns romances são publicados pelas melhores editoras; outros não. Alguns se tornam canônicos; outros desaparecem. E isto depende em parte do que Said chama de "afiliações", ou as relações entre as obras propriamente ditas e diversas instituições, agências, classes e assim por diante, ou o que Bourdieu chamaria de "instâncias de consagração". A prática literária se define, portanto, tanto em termos de uma intertextualidade propriamente literária quando em termos do quadro institucional que sustenta a literatura de múltiplas maneiras. O que me interessa aqui não é a obra literária em si, mas a trajetória de cada autor dentro de uma rede específica de afiliações que contribuem para a construção de sua posição no campo.

Naturalmente, cada trajetória é diferente, e por isso a abordagem específica também tem que ser diferente.

No caso de Cassiano Ricardo, discuto o lugar do grupo Verde-Amarelo/Anta, dentro do contexto mais amplo do modernismo, e a elaboração crescente de uma ideologia autoritária. Em relação a Mário de Andrade, focalizo o seu conceito do papel social do artista ou, mais especificamente, o que chamo de "intenção" artística e cultural. No capítulo sobre Octávio de Faria, representante da direita católica, examino várias facetas do desenvolvimento do seu pensamento, que Maria Teresa Sadek caracterizou como um "autoritarismo perdedor", na Tragédia burguesa. No último capítulo exploro a construção de Graciliano Ramos como escritor de esquerda, concentrando-me principalmente no período até 1936.

Para quem se interessar, uma versão inicial do capítulo introdutório, traduzida por você, foi publicada, em 1995, no número 26 da Revista USP, com o título "A dinâmica 
do campo literário brasileiro - 1930-1945". Nesse artigo, delineio alguns dos argumentos centrais de outros capítulos como "Authoritarian Fiction: Octávio de Faria’s Tragédia burguesa", "The Institutionalization of Brazilian Modernism", "Notes on a Conservative Vanguard: The Case of Verde-Amarelo/Anta", "Art and Intention in Mário de Andrade", e "Graciliano and Politics in Alagoas", já publicados (ou em vias de, como é o caso do ensaio sobre Graciliano) em revistas e coletâneas dispersas durante mais anos que gostaria de lembrar. Devo terminar o livro nos próximos meses, e depois pretendo voltar a escrever sobre cinema, talvez atualizando o meu livro sobre a indústria cinematográfica brasileira.

\section{OUTROS LIVROS DO AUTOR}

Além do livro já mencionado, Randal Johnson também publicou os seguintes (além de dezenas de artigos):

Brazilian Cinema. Rutherford, N.J.: Fairleigh Dickinson University Press, 1982. Rpt. Austin: University of Texas Press, 1988. Coedited with Robert Stam. Expanded rpt. New York: Columbia University Press, 1995.

Cinema Novo x 5: Masters of Contemporary Brazilian Film. Austin: University of Texas Press, 1984.

The Film Industry in Brazil: Culture and the State. Pittsburgh: University of Pittsburgh Press, 1987.

Tropical Paths: Essays on Modern Brazilian Literature. New York: Garland Publishing, 1993. Organizer, editor, author of introduction.

Pierre Bourdieu. The Field of Cultural Production: Essays on Art and Literature. Cambridge, England: Polity Press, 1993. Editor, author of introduction. U. S. edition: New York: Columbia University Press, 1993.

Antônio das Mortes. Wiltshire, England: Flicks Books, 1998.

Black Brazil: Culture, Identity, and Social Mobilization. Los Angeles: UcLA Latin American Center. 1999. Co-edited with Larry Crook.

Manoel de Oliveira. Champaign/Urbana: University of Illinois Press, 2007.

The Talking Pictures of Manoel de Oliveira. Exhibition catalog. Los Angeles: UCla Film and Television Archive, 2008.

Joe Wallach. Meu Capitulo na TV Globo. Rio de Janeiro: Topbooks, 2011. Editor. 